\title{
Maspin polymorphism associated with apoptosis susceptibility and in vivo tumorigenesis
}

\author{
HYE-LIM JANG ${ }^{1 *}$, EUNSOOK NAM ${ }^{1 *}$, KON HO LEE $^{2}$, \\ SEONYONG YEOM ${ }^{1}$, HEE JUNG SON ${ }^{3}$ and CHAEHWA PARK ${ }^{1}$ \\ ${ }^{1}$ Cancer Center, Samsung Medical Center, Sungkyunkwan University School of Medicine, Seoul 135-710; \\ ${ }^{2}$ Division of Applied Life Science, PMBBRC and EB-NCRC, Gyeongsang National University, Jinju 660-701; \\ ${ }^{3}$ Department of Medicine, Samsung Medical Center, Sungkyunkwan University School of Medicine, Seoul 135-710, Korea
}

Received March 24, 2008; Accepted May 14, 2008

DOI: 10.3892/ijmm_00000027

\begin{abstract}
Maspin is a tumor suppressor protein that stimulates apoptosis and inhibits motility, invasion and cancer metastasis. We report on a previously uncharacterized Pro/Ser ( $\mathrm{C}$ to $\mathrm{T}$ ) polymorphism at amino acid 176 of the human maspin protein. We analyzed the maspin mutation in 17 cancer cell lines and 36 cancer tissues. Association of polymorphic variants on apoptosis, colony formation and in vivo tumor formation was evaluated. Mutant maspin was found to be frequently expressed in gastric cancer (32/36, $89 \%)$. According to predicted maspin tertiary structure, the polymorphic residue is located on the surface of the protein proximal to the reactive site loop domain, and thus may significantly affect the protein interactions of maspin. Stable expression of the Pro and Ser forms of maspin in lung cancer cells revealed that cells expressing Ser176 maspin showed significantly decreased apoptosis and increased colony formation compared with those expressing Pro176 maspin. In a mouse model, cells expressing Ser176 maspin showed a higher rate of tumor formation in vivo than those harboring Pro176 maspin. Therefore, P176S (C526T) substitution of maspin may result in a partial loss of the tumor suppressor function of this protein, contributing to decreased susceptibility to apoptosis and malignant progression.
\end{abstract}

\section{Introduction}

Maspin, a tumor suppressor that is encoded by a 7-exon gene on chromosome 18q21.3 (1), comprises a 42-kDa protein containing an $\mathrm{N}$-terminal domain for extracellular secretion

Correspondence to: Dr Chaehwa Park, Cancer Center, Samsung Medical Center, Sungkyunkwan University School of Medicine, 50 Irwon-Dong, Seoul 135-710, Korea

E-mail: cpark@skku.edu

${ }^{*}$ Contributed equally

Key words: maspin, polymorphism, apoptosis, tumorigenesis and a typical serpin domain termed reactive site loop (RSL) (2). Despite having high sequence homology to members of the serpin protease inhibitor family, maspin lacks protease inhibitor activity $(3,4)$. Maspin was originally identified as a differentially expressed tumor suppressor gene in breast cancer $(5,6)$. Consistent with this tumor suppressor function, impaired expression of maspin has been reported in several epithelial-type human malignancies, including breast, prostate and lung cancer (7-9). Contrary to these findings, however, significant correlation of maspin expression and clinical aggressiveness has been reported in pancreatic, ovarian and gastric cancers (10-12).

During carcinogenesis, tumor suppressors often suffer from deletions, point mutations and overexpression. One previous study reported a mutation in the maspin mRNA from a cancer cell line (13), but the precise function of this mutant maspin was not investigated. Here, we sought to identify and characterize a novel somatic mutation of maspin in human cancer. Using human cancer cell lines, we found the first evidence of a prevalent $(8 / 13,62 \%) \mathrm{C} / \mathrm{T}$ polymorphism encoding a Pro/Ser point mutation at amino acid 176 in the human maspin gene. Mutant maspin was found to be frequently expressed in gastric cancer (32/36, 89\%). Wildtype P176 maspin effectively stimulated apoptosis and suppressed colony formation of NCI-H157 cells and decreased tumorigenesis in lung cancer cells in nude mice, whereas mutant Ser176 maspin was associated with decreased in vitro apoptosis and increased in vivo tumorigenesis. Thus, we suggest that the novel maspin polymorphism identified for the first time in the present study may differentially affect carcinogenesis and chemosensitivity.

\section{Materials and methods}

Cell lines and tissue samples. Tumor tissue samples were available from 40 patients diagnosed with gastric cancer at Samsung Medical Center (Seoul, Korea). Human lung cancer cell lines A549, NCI-H23, -H157, -H322, -H358, -H520 and -H661 were purchased from the American Type Culture Collection (Rockville, MD). Human gastric cancer cell lines SNU5, SNU16, SNU601, SNU620, SNU638, SNU668, MKN-1, MKN-28, MKN-45 and MKN-74 were obtained 
from the Korean Cell Line Bank (Seoul, Korea). The cells were cultured in RPMI-1640, supplemented with $10 \%$ fetal bovine serum, $1 \mathrm{mM} \mathrm{NaCO}, 2 \mathrm{mM} \mathrm{L}$-glutamine and penicillinstreptomycin, in a $5 \% \mathrm{CO}_{2}$ atmosphere at $37^{\circ} \mathrm{C}$.

Maspin mutation analysis. The mRNAs encoding maspin were screened for mutations using a combination of RT-PCR and sequencing. Total RNA was isolated from the various cancer cell lines using an RNeasy mini kit (Qiagen, Hilden, Germany) and treated with DNase I (Qiagen). cDNA was synthesized by reverse transcription-PCR using Superscript II reverse transcriptase (Invitrogen, Carlsbad, CA). The cDNA fragments encoding maspin were isolated using two sets of primer sequences designed from the coding region of the human maspin as follows: first half (670 bp product), 5'CTCGCTTGCCTGTTCCTT-3' (sense) and 5'-GGCCT CCATGTTCATCATCT-3' (antisense); second half (680-bp product), 5'-GTTGGCAAGTGGATGAAG-3' (sense) and 5'CGGCATCCACAGAAAAGTCA-3' (antisense). The PCR conditions consisted of 25 cycles of $95^{\circ} \mathrm{C}$ for $30 \mathrm{sec}, 57^{\circ} \mathrm{C}$ for $30 \mathrm{sec}$, and $72^{\circ} \mathrm{C}$ for $60 \mathrm{sec}$, followed by a final incubation at $72^{\circ} \mathrm{C}$ for $7 \mathrm{~min}$. The PCR reactions were performed using the Taq DNA polymerase (Bionics, Seoul, Korea), and the PCR products were directly sequenced.

After the C526T mutation in exon 5 was identified from cDNA samples, PCR amplification and DNA sequencing were used to validate the mutation in genomic DNA. Nested PCR primers were designed to amplify exon 5 along with its flanking intronic sequences. The primers were chosen with the assistance of the computer program Primer3 (wwwgenome.wi.mit.edu/cgi-bin/primer/primer3_www.cgi), and are as follows: first round (700-bp product), 5'-CTG CCT GAC ACA GAA TAG GCA-3' (sense) and 5'-AGC TTT CCT CGC TGG GTT ACA-3' (antisense); nested PCR (340-bp product), 5'-AGG CCT TAC ATG GTG TGA CTC CAT-3' (sense) and 5'-GAT TTA TGC CCC ACT CTG TCC CTA$3^{\prime}$ (antisense). The PCR conditions consisted of 35 cycles of $95^{\circ} \mathrm{C}$ for $30 \mathrm{sec}, 52^{\circ} \mathrm{C}$ for $30 \mathrm{sec}$, and $72^{\circ} \mathrm{C}$ for $60 \mathrm{sec}$, followed by a final incubation at $72^{\circ} \mathrm{C}$ for $7 \mathrm{~min}$. Most of the above PCR reactions were performed using the Taq DNA polymerase, and the resulting fragments were directly sequenced.

Plasmid construction and site-directed mutagenesis. The C to $\mathrm{T}$ (Pro176Ser) mutation was introduced by site-directed mutagenesis using a PCR-based approach (mutagenic primer 5'-AAG TGG ATG AAG AAA TTT TCT GAA TCA GAA$\left.3^{\prime}\right)$. The mutation was confirmed by sequencing, and the wild-type and mutant maspin cDNA sequences were cloned into the pCMVTaq4C (Invitrogen) mammalian expression vector. Human lung cancer NCI-H157 cells were transfected with plasmids encoding wild-type maspin, mutant maspin, or the control vector using effectine (Qiagen), and stably transfected cells were selected by growth in the presence of G418. Maspin expression was evaluated by Western blot analysis (as follows).

Comparison of maspin structures. The previously identified structures of the mutant (Ser176; PDB code 1XQG) (14) and wild-type (PDB code WZ9) (15) maspin proteins were superposed using the LSQKAB program of the CCP4 Suit
(16). The figures representing the main chain traces were generated using PyMol (17).

Biochemical analyses of mutant maspin function. Western blot analysis was performed to detect the protein expression of maspin and caspase-3. Briefly, cells or tissues were lysed in RIPA buffer $\left(20 \mathrm{mM} \mathrm{Na}_{2} \mathrm{PO}_{4}, \mathrm{pH} 7.4,150 \mathrm{mM} \mathrm{NaCl}\right.$, $1 \%$ Triton $\mathrm{X}-100,1 \%$ aprotinin, $1 \mathrm{mM}$ phenylmethylsulfonyl fluoride, $100 \mathrm{mM} \mathrm{NaF}$, and $\left.2 \mathrm{mM} \mathrm{Na}_{3} \mathrm{VO}_{4}\right)$. Equal amounts of cell lysates were resolved by $8 \%$ SDS-PAGE and subjected to Western blot analysis using antibodies against maspin (Pharmingen, San Diego, CA) and $\alpha$-tubulin or B-actin (Sigma) for loading controls, and the results were visualized with an enhanced chemiluminescence system (Amersham, Arlington Heights, IL). Western blotting with caspase-3 antibody was used to detect caspase cleavage, and caspase- 3 activity was measured using a caspase-3 activity assay kit from Peptron (Seoul, Korea). Apoptosis was evaluated using an Annexin V-PE apoptosis detection kit (BD Biosciences, San Jose, $\mathrm{CA}$ ), according to the manufacturer's instructions. Briefly, the cells were cultured for $24 \mathrm{~h}$, treated with $500 \mathrm{nM}$ staurosporine for $2 \mathrm{~h}$, and then harvested and examined for apoptosis by fluorescence-activated cell sorter (FACS) analysis. Cells that stained positive for Annexin V-PE and negative for 7AAD underwent apoptosis.

Colony formation assay. Exponentially growing NCI-H157 cells stably expressing maspin or control vector, were seeded in triplicate in $60-\mathrm{mm}$ dishes at a density of $1 \times 10^{2}$ cells per dish. After incubation at $37^{\circ} \mathrm{C}$ for 8 days, the cells were stained with $0.005 \%$ crystal violet. Colonies, which were defined as groups of a minimum of 50 cells, were counted using phase contrast microscopy.

Preparation of tumor xenografts in immunodeficient mice. Four-week-old female athymic nude mice (CD1, nu/nu) were purchased from Charles River Laboratory (Atsugi, Japan). Approximately 1 week after the mice arrived, NCI-H157 cells stably expressing maspin or control vector, were harvested and suspended in PBS. The mice were anesthetized using isoflurane inhalation, and $5 \times 10^{6}$ cells in a final volume of $100 \mu 1$ were injected subcutaneously into the left flank of each mouse, using 1-ml syringes with 26.5-gauge needles. All experiments were performed in triplicate and a representative result was given. The tumor volumes were estimated according to the formula $\mathrm{V}=\mathrm{ab}^{2} / 2$, where $\mathrm{a}$ is the long axis and $b$ the short axis. Mice were maintained and sacrificed according to institutional guidelines, and the procedures were approved by the Institutional Committee on the Use and Care of Animals and Recombinant DNA Research.

\section{Results and discussion}

Maspin polymorphism in cancer cells and tissues. Our mutational analysis of various human cancer cell lines and tumor tissues revealed nucleotide changes predicted to cause three missense mutations in the maspin protein sequence, namely P176S, L187V and I319V. Amino acid sequence alignments of maspin proteins from different species showed conservation of Pro176, which lies far from the reactive site 
A

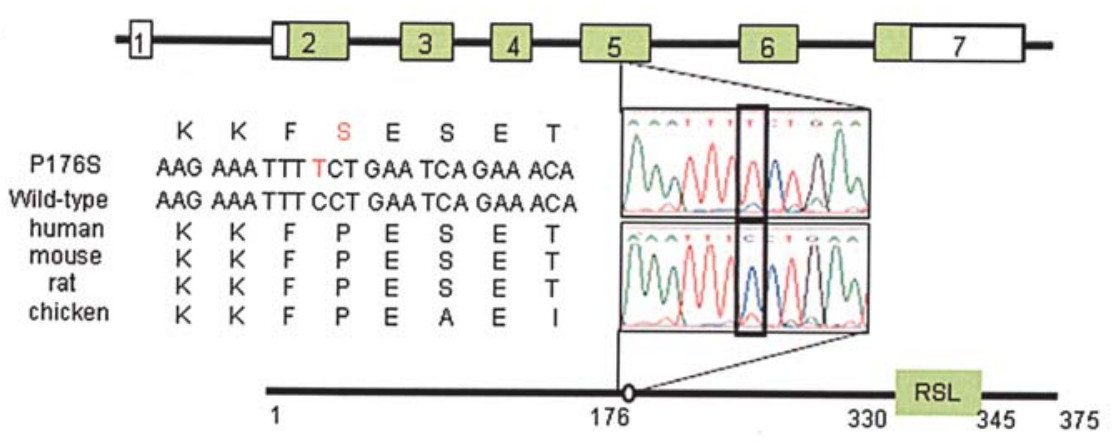

$\mathrm{B}$

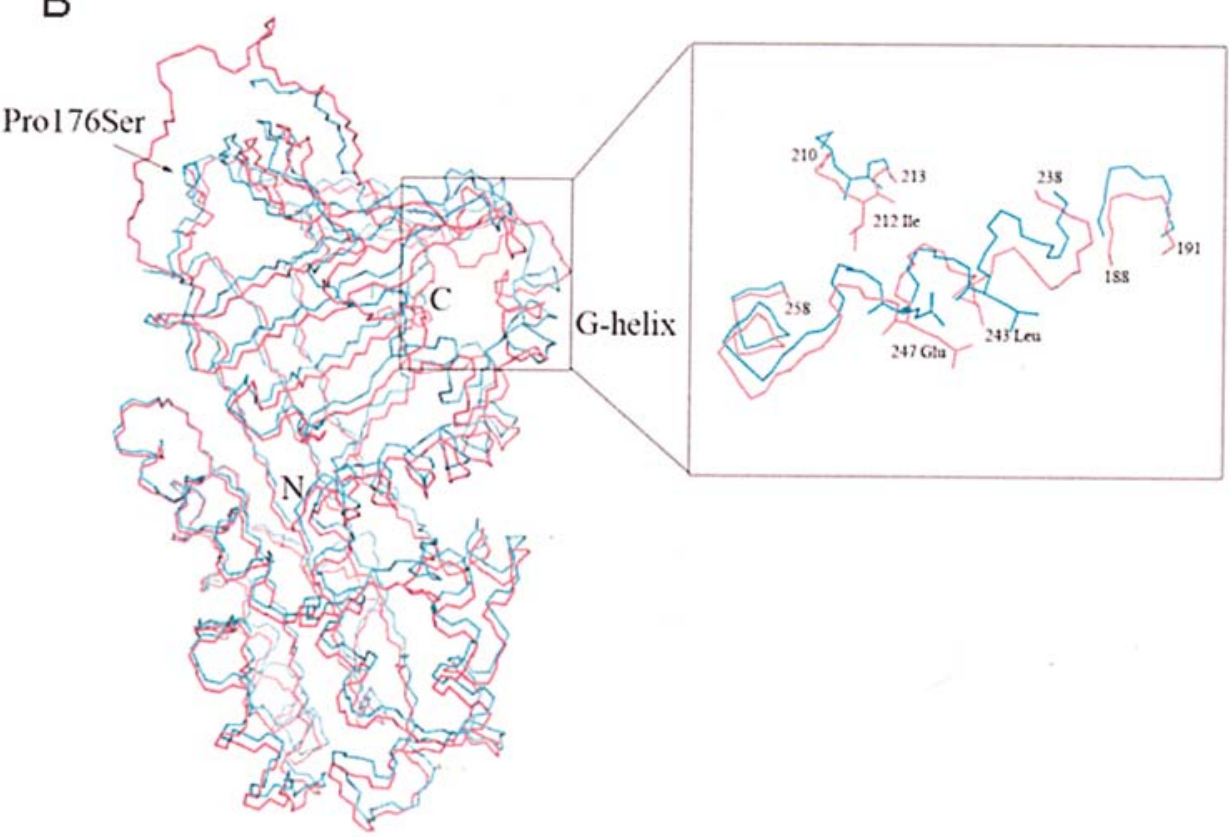

C

Polymorphism of maspin in human cancer

\begin{tabular}{|c|c|c|c|c|c|c|c|}
\hline Cell lines & Type & Cases & $\%$ & Tissues & Type & Cases & $\%$ \\
\hline \multirow{3}{*}{ Lung Ca. } & Exp & $3 / 7$ & 43 & \multirow{7}{*}{ Gastric Ca. } & & & \\
\hline & & $5 / 7$ & 71 & & & & \\
\hline & $M / \operatorname{Exp}$ & $1 / 3$ & 33 & & Exp & $36 / 38$ & 95 \\
\hline \multirow{4}{*}{ Gastric Ca. } & & & & & & $35 / 40$ & 88 \\
\hline & Exp & $10 / 10$ & 100 & & $M / \operatorname{Exp}$ & $32 / 36$ & 89 \\
\hline & & $7 / 10$ & 70 & & & & \\
\hline & $M / \operatorname{Exp}$ & $7 / 10$ & 70 & & & & \\
\hline
\end{tabular}

Figure 1. Mutation and overexpression of maspin in gastric cancer. (A) Sequence analysis identified a single nucleotide substitution within exon 5 of maspin from several cancer cell lines and tissues. The mutation changes an amino acid far from the reactive site loop (RSL). (B) Comparison of maspin structures. The wild-type (WZ9) and P176S mutant (1XQG) forms are superposed and amino acid 176 is marked with an arrow. The region around the Ghelix was rotated approximately 90 degrees to show the distinctive conformations (boxed). The main chain trace of the WZ9 A chain is shown in cyan and that of $1 \mathrm{XQG}$ in magenta. C, Frequencies of maspin expression and mutation in cancer cell lines and paired gastric tissues ( $\mathrm{T}$, tumor; N, normal). Exp, protein expression of maspin; M, mutation of maspin gene in genomic DNA; M/Exp, mutation of maspin genomic DNA in maspin-positive cases as evaluated by Western blot analysis. P176S-specific maspin antibody was not available, thus we used anti-maspin antibody that recognized both wild type and mutant maspin.

loop (RSL, 330-345) of the protein (Fig. 1A). As shown in Fig. 1C, the P176S (C526T) somatic missense mutation was detected in 7/10 (70\%) gastric cancer cell lines, 5/7 (71\%) lung cancer cell lines, and 35/40 (88\%) gastric cancer tissue samples. This indicates that $\mathrm{P} 176 \mathrm{~S}$ could be a polymorphism rather than a mutation. Mutant maspin protein was found to be frequently expressed in gastric cancer, 32/36 (89\%). Although these frequencies do not support the hypothesis that the mutation may contribute to carcinogenesis, these observations prompted us to investigate the possibility that P176S maspin may play a differential role in epithelial cells. The appearance of a different genetic allele that has lost its normal activity, which is very common among tumor suppressors, may support the functional significance of maspin as a tumor suppressor.

Structural differences between wild-type and Pro176Ser mutant maspin. Four maspin structures have been reported to 

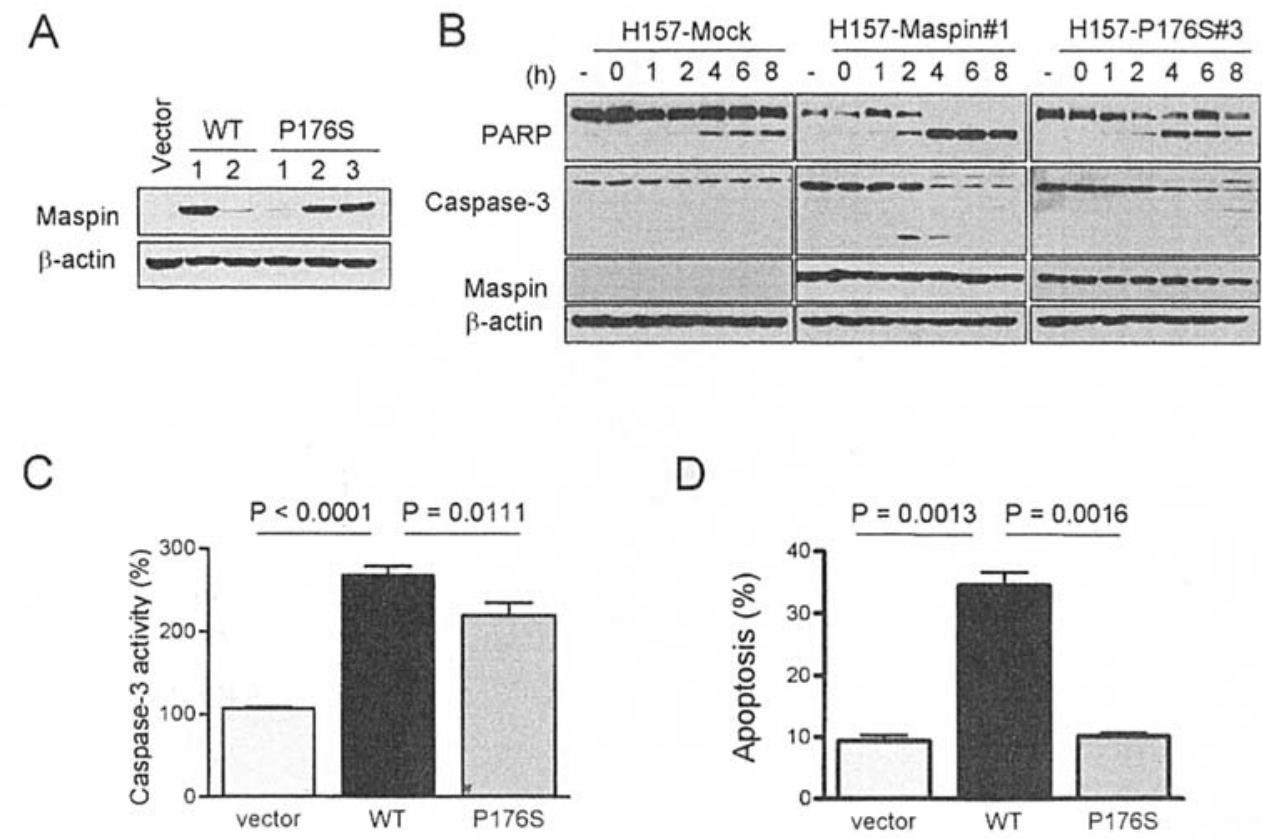

Figure 2. Effect of the P176S mutation on apoptosis. NCI-H157 cells were transfected with plasmids encoding empty vector, maspin, and mutant (P176S) maspin. Analysis of maspin expression in the stably transfected cell lines (A). After treatment with $500 \mathrm{nM}$ staurosporine (STS), whole-cell protein lysates were prepared from wild-type (WT) maspin expressing clone (\#1) and mutant maspin-expressing clone (\#3) and subjected to Western blot analysis for cleavage and activation of PARP and caspase-3 (B). The cells were also harvested for caspase activity analysis (C) or for identifying cells that are undergoing apoptosis (D) after treatment with STS.

date, varying in terms of resolution. These include structures generated at resolutions of $3.1 \AA$ (two structures; PDB codes 1XQJ and 1XQG) (14), $2.8 \AA$ (PDB code XU8) and $2.1 \AA$ (PDB code WZ9) (15). We found that the two lowerresolution maspin structures carried the Ser mutation at residue 176, whereas the high-resolution maspin structures had Pro at that position. Thus, we compared 1XQG (Ser176) and WZ9 (Pro176) to see if there were any evident structural differences due to the P176S amino acid substitution. Superposition (Fig. 1B) revealed that the overall structures, including the region around amino acid 176, were almost the same between 1XQG and WZ9. However, we observed significant differences in the region around the G-helix, as mentioned previously (15). The main chain of the $1 \mathrm{XQG}$ low-resolution structure is positioned lower than that of the WZ9 high-resolution structure. In addition, the side chains in 1XQG point toward the middle of the protein, covering the surface, whereas those of WZ9 point toward the solvent, baring the surface around the G-helix (Fig. 1B). These closed and open conformations around the G-helix form distinctive protein surfaces that could modify protein-protein interactions. Therefore, the amino acid substitution might have a substantial effect on the interaction of maspin with other proteins. To test this hypothesis, we compared the activity of the wild-type and mutant proteins.

Functional analysis of Pro176Ser mutant maspin in vitro. To our knowledge, this is the first report of a maspin mutation that might affect its tumor suppressor function. Although the frequency of maspin mutation was higher in gastric cancer, all of the 10 tested gastric cancer cell lines highly expressed maspin. Thus we investigated the effect of the maspin mutation in a maspin-negative lung cancer cell line NCIH157. In order to evaluate the biological significance of maspin P176S, we generated NCI-H157 cells stably expressing wild-type maspin (H157/Pro), mutant maspin (H157/Ser) and the empty vector (H157/C). Western blot analysis using an anti-maspin antibody showed that the stable transfectants expressed maspin, whereas parental NCI-H157 cells did not (Fig. 2A). For further analysis we used the stable transfectants expressing equal amounts of maspin, wild-type clone 1 and P176S clone 3. Maspin has previously been shown to activate Bax and induce apoptosis (18). As shown in Fig. 2, our results revealed that cleavage of caspase-3 or PARP was stimulated by wild-type maspin, but not by mutant maspin or the vector control (Fig. 2B). Similarly, caspase-3 activity was significantly induced by wild-type maspin in the presence of staurosporine (wild-type vs. control, $\mathrm{P}<0.0001$ ), but the ability of the mutant maspin to activate caspase-3 was significantly decreased (wild-type vs. mutant, $\mathrm{P}=0.0111$ ) (Fig. 2C). Cells undergoing apoptosis were analyzed by flow cytometry. After $2 \mathrm{~h}$ of staurosporine treatment, apoptosis (Annexin V-PE positive and 7-AAD negative) was induced in $\sim 35 \%$ of cells by wild-type maspin $(\mathrm{P}=0.0013)$, but not by mutant maspin (Fig. 2D). Next, the effect of mutant maspin on cell growth was evaluated using colony formation assays. As shown in Fig. 3A, colony formation was similar in mutant maspin-expressing cells and control cells $(\mathrm{P}>0.05)$, whereas it was greatly suppressed in cells expressing wild-type maspin (wild-type vs. control, $\mathrm{P}=0.0011$; wild-type vs. mutant, $\mathrm{P}=0.0009$ ). To avoid clonal variation, pooled (>30 colonies) G418-resistant (600 ng/ml) stable transfectants were established using empty vector, wild-type or mutant maspin expression vector for cell lines 
A
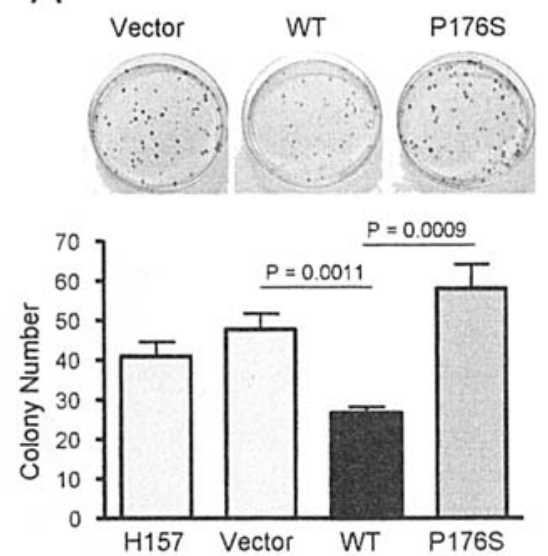

B

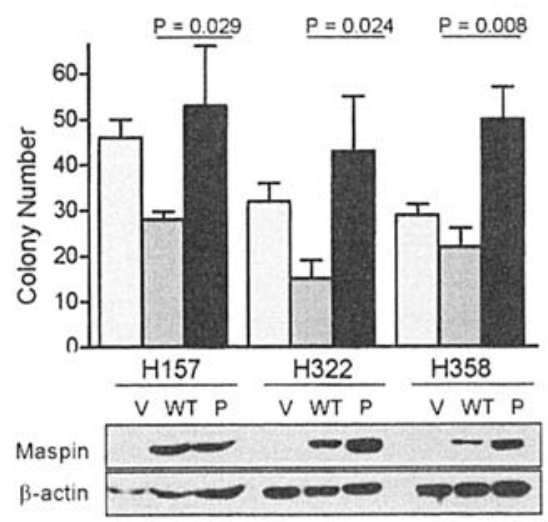

Figure 3. The effect of the P176S mutation on colony formation. (A) Cells stably expressing mutant maspin show decreased colony formation ability compared to wild-type maspin. An equal number of cells were plated in 60 -mm dishes, and colony-forming ability was evaluated after 8 days of continuous culture. (B) Long-term survival of NCI-H157, H322 and H358 cells was decreased by ectopic expression of wild-type maspin but not by the P176S mutant. Stable transfectants were established for these cell lines using wild-type maspin (WT), P176S mutant (P) or empty vector (V) and >30 G418resistant colonies were pooled to avoid clonal variations. To test cell survival, cells were treated with doxorubicin (500 $\mathrm{nM}$ ) for $1 \mathrm{~h}$ and incubated for 9 days. Clonogenic survival was determined by staining colonies with crystal violet and colonies were counted using phase contrast microscopy. The values shown represent the average and SD of three individual experiments.

NCI-H157, -H322 and -H358. We then analyzed the effect of maspin expression on long-term survival of these cells by clonogenic assay (Fig. 3B). After treatment with doxorubicin, cell lines expressing P176S maspin did not show a big difference in colony formation when compared with the empty vector-transfected control group. In contrast, wildtype maspin-expressing cell lines showed significant decrease in colony number $(\mathrm{H} 157 / \mathrm{WT}$ vs. H157/P, P=0.029; H322/WT vs. H322/P, $\mathrm{P}=0.024$; H358/WT vs. H358/P, $\mathrm{P}=0.008)$. These results demonstrate that wild-type maspin can effectively suppress cell survival in these cancer cell lines.

In vivo tumorigenesis. To examine whether the enhanced colony formation and decreased apoptosis of cells expressing P176S mutant maspin leads to enhanced tumor progression in vivo, we measured tumorigenesis in athymic nude mice following subcutaneous injections of NCI-H157 cells expressing wild-type maspin, mutant maspin, or the vector control. As shown in Fig. 4, the H157/C and H157/Ser cells formed tumors $\sim 929 \pm 316 \mathrm{~mm}^{3}$ and $23 \pm 8 \mathrm{~mm}^{3}$ in size over 37 days, whereas the H157/Pro cells developed tumors that were only $1.7 \pm 0.5 \mathrm{~mm}^{3}$ in size during the same period (H157 /Pro vs. H157/C, P=0.0189; H157/Pro vs. H157/Ser, P=0.0289). Intriguingly, the tumors formed by H157/Pro disappeared thereafter. By week 6, the control cells had formed tumors $\sim 2779 \pm 1689 \mathrm{~mm}^{3}$ in size, the mice injected with maspintransfected cells no longer showed palpable tumors, and those injected with P176S mutant maspin-expressing cells harbored tumors that were only $77 \pm 56 \mathrm{~mm}^{3}$ (H157/Pro vs. $\mathrm{H} 157 /$ Ser, $\mathrm{P}=0.0279$, Fig. 4). Thus, our in vivo data strongly support the idea that the P176S mutation in maspin decreases the tumor suppression of maspin to some degree.

Differential colony formation and caspase activation may at least partially account for the differences in in vivo tumorigenesis between cells expressing wild-type and P176S mutant maspin. Although the P176S mutant maspin did not

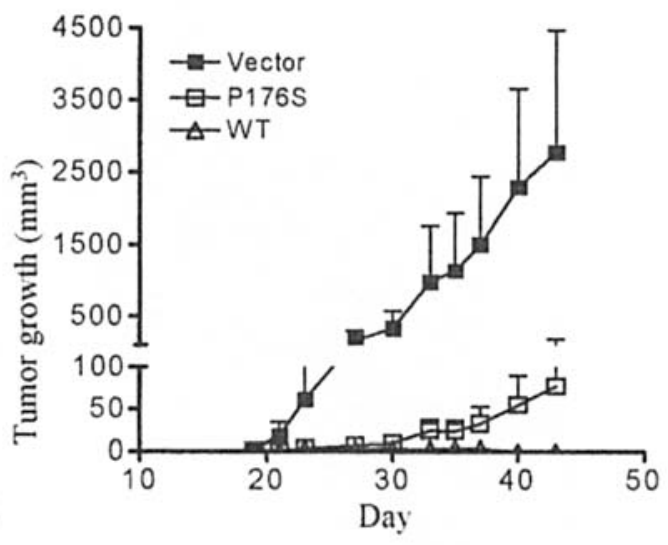

Effects of maspin on tumor growth $(D+3)$

\begin{tabular}{lccc}
\hline group & tumor $(\mathrm{n} / \mathrm{n})$ & tumor size & $P *$ \\
\hline Vector & $3 / 5$ & $2779 \pm 1689$ & - \\
Wild Type & $0 / 5$ & 0 & $0.01699^{\dagger}$ \\
P176S & $2 / 5$ & $76.8 \pm 56.0$ & $0.0279:$ \\
\hline
\end{tabular}

paired $t$-test, vector vs WT, :WT vs P176S

Figure 4. Effects of the P176 maspin polymorphism on in vivo tumor growth in nude mice. Lung cancer cells (NCI-H157) stably expressing maspin displayed reduced tumorigenesis after subcutaneous implantation into athymic (nu/nu) mice. A total of $5 \times 10^{6}$ H157/c, H157/mas, or H157/P176S cells were subcutaneously injected into mice and the tumor size was measured periodically. A representative result from three independent experiments is presented, with tumor volumes given as the average size in $\mathrm{mm}^{3} \pm \mathrm{SE}$ of tumors in 5 mice.

show any tumor suppressor activity in our colony formation assay, tumor formation by mutant-expressing cells was still far lower than that by control cells, indicating that maspin may have a multifaceted tumor suppressive function in the in vivo tumor microenvironment. Thus, while we cannot 
conclude that this apoptosis-inactivating mutation plays a causal role in human cancers, our in vivo experiments in a mouse model suggest that the P176S substitution in the maspin protein has functional significance.

In conclusion, we herein report for the first time that residue Pro176 of maspin is frequently mutated to Ser in human cell lines and cancer tissues, and we further show that this change leads to a significant alteration in the surface structure of the protein, as well as to decreased apoptosis and enhanced colony formation in vitro and increased tumorigenesis in vivo. Collectively, the present findings strongly suggest that the newly identified mutation in maspin may contribute to tumor progression and increased resistance to apoptosis. Although the clinical implication of the maspin polymorphism is yet to be determined, it is important to clarify if the P176S mutation is associated with a differential response to chemotherapy.

\section{Acknowledgements}

This study was supported by a grant (KRF-2005-015C00478) from the Korea Research Foundation.

\section{References}

1. Schneider SS, Schick C, Fish KE, Miller E, Pena JC, Treter SD, Hui SM and Silverman GA: A serine proteinase inhibitor locus at $18 \mathrm{q} 21.3$ contains a tandem duplication of the human squamous cell carcinoma antigen gene. Proc Natl Acad Sci USA 92: 3147-3151, 1995.

2. Sheng S, Pemberton PA and Sager R: Production, purification, and characterization of recombinant maspin proteins. J Biol Chem 269: 30988-30993, 1994.

3. McGowen R, Biliran H Jr, Sager R and Sheng S: The surface of prostate carcinoma DU145 cells mediates the inhibition of urokinase-type plasminogen activator by maspin. Cancer Res 60: 4771-4778, 2000

4. Pemberton PA, Wong DT, Gibson HL, Kiefer MC, Fitzpatrick PA, Sager R and Barr PJ: The tumor suppressor maspin does not undergo the stressed to relaxed transition or inhibit trypsin-like serine proteases. Evidence that maspin is not a protease inhibitory serpin. J Biol Chem 270: 15832-15837, 1995.
5. Zou Z, Anisowicz A, Hendrix MJ, Thor A, Neveu M, Sheng S, Rafidi K, Seftor E and Sager R: Maspin, a serpin with tumorsuppressing activity in human mammary epithelial cells. Science 263: 526-529, 1994

6. Hendrix MJ: De-mystifying the mechanism(s) of maspin. Nat Med 6: 374-376, 2000.

7. Sheng S, Carey J, Seftor EA, Dias L, Hendrix MJ and Sager R: Maspin acts at the cell membrane to inhibit invasion and motility of mammary and prostatic cancer cells. Proc Natl Acad Sci USA 93: 11669-11674, 1996.

8. Machtens S, Serth J, Bokemeyer C, Bathke W, Minssen A, Kollmannsberger C, Hartmann J, Knuchel R, Kondo M, Jonas U and Kuczyk M: Expression of the p53 and Maspin protein in primary prostate cancer: correlation with clinical features. Int $\mathbf{J}$ Cancer 95: 337-342, 2001.

9. Kim S, Han J, Kim J and Park C: Maspin expression is transactivated by p63 and is critical for the modulation of lung cancer progression. Cancer Res 64: 6900-6905, 2004.

10. Maass N, Hojo T, Ueding M, Luttges J, Kloppel G, Jonat W and Nagasaki K: Expression of the tumor suppressor gene Maspin in human pancreatic cancers. Clin Cancer Res 7: 812-817, 2001.

11. Sood AK, Fletcher MS, Gruman LM, Coffin JE, Jabbari S, Khalkhali-Ellis Z, Arbour N, Seftor EA and Hendrix MJ: The paradoxical expression of maspin in ovarian carcinoma. Clin Cancer Res 8: 2924-2932, 2002.

12. Akiyama Y, Maesawa C, Ogasawara S, Terashima M and Masuda T: Cell-type-specific repression of the maspin gene is disrupted frequently by demethylation at the promoter region in gastric intestinal metaplasia and cancer cells. Am J Pathol 163: 1911-1919, 2003

13. Umekita Y, Hiipakka RA and Liao S: Rat and human maspins: structures, metastatic suppressor activity and mutation in prostate cancer cells. Cancer Lett 113: 87-93, 1997.

14. Al-Ayyoubi M, Gettins PG and Volz K: Crystal structure of human maspin, a serpin with antitumor properties: reactive center loop of maspin is exposed but constrained. J Biol Chem 279: 55540-55544, 2004.

15. Law RH, Irving JA, Buckle AM, Ruzyla K, Buzza M, Bashtannyk-Puhalovich TA, Beddoe TC, Nguyen K, Worrall DM, Bottomley SP, Bird PI, Rossjohn J and Whisstock JC: The high resolution crystal structure of the human tumor suppressor maspin reveals a novel conformational switch in the G-helix. J Biol Chem 280: 22356-22364, 2005.

16. Collaborative Computational Project, Number 4. The CCP4 suite: programs for protein crystallography. Acta Crystallogr D Biol Crystallogr 50: 760-763, 1994.

17. DeLano WL: The PyMOL Molecular Graphics System 2002 on world wide web, http://www.pymol.org.

18. Liu J, Yin S, Reddy N, Spencer C and Sheng S: Bax mediates the apoptosis-sensitizing effect of maspin. Cancer Res 64: 1703-1711, 2004. 